\title{
A ética da virtude na prática da equipe de saúde da familia
}

Virtue ethics in family health team's practice

La ética de las virtudes en la práctica del equipo de salud de la familia

Cecília Maria Lima Cardoso Ferraz ${ }^{1}$ @ https://orcid.org/0000-0001-6897-3798)

Carolina da Silva Caram ${ }^{1}$ i h htps://orcid.org/0000-0001-6219-3301

Maria José Menezes Brito' ic https://orcid.org/0000-0001-9183-1982

Como citar:

Ferraz CM, Caram CS, Brito MJ. A ética da virtude na prática da equipe de saúde da família. Acta Paul Enferm. 2022;35:eAPE02831.

DOI

http://dx.doi.org/10.37689/acta-ape/2022A002831

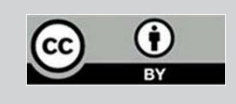

Descritores

Assistência centrada no paciente; Estratégia saúde da família; Ética; Equipe de assistência ao paciente; Prática

profissional

Keywords

Ethics; Family health strategy; Patient care team; Patientcentered care; Professional practice

Descriptores

Atención dirigida al paciente; Estrategia de salud familia ; Ética; Grupo de atención al paciente;

Práctica profesional

Submetido

29 de Setembro de 2020

Aceito

23 de Março de 202

Autor correspondente Cecília Maria Lima Cardoso Ferraz E-mail: cecilia.lima@unifemm.edu.br

Editor Associado (Avaliação pelos pares) Paula Hino (https://orcid.org/0000-0002-1408-196X) Escola Paulista de Enfermagem, Universidade Federal de São Paulo, São Paulo, SP, Brasil

\section{Resumo}

Objetivo: Compreender a prática da equipe de saúde da família sob o prisma da ética da virtude.

Métodos: Estudo de caso único de abordagem qualitativa, realizado entre janeiro e julho de 2019, em Estratégias de Saúde da Família, de um município do interior de Minas Gerais. Os participantes foram médicos, enfermeiros, técnicos de enfermagem e agentes comunitários de saúde, totalizando 35 profissionais das equipes da Estratégia Saúde da Família. Os dados foram coletados por meio de entrevistas e observação e, analisados por meio da análise de conteúdo, com auxílio do software Atlas.ti.

Resultados: A prática da equipe de saúde da família se desenvolve pelo cuidado centrado nos usuários, na busca de atender suas necessidades objetivas e subjetivas. Contudo, existem obstáculos que transitam na interface entre a legalidade/burocracia (ethos burocrático) referente ao atendimento de normas preconizadas para organização e funcionamento do serviço e o ethos profissional relacionado ao compromisso dos profissionais com as pessoas.

Conclusão: A prática da equipe de saúde da família na ótica da ética da virtude permite reconhecer que profissional e paciente são agentes morais que se orientam por valores e virtudes na busca pelo bem interno de suas vidas e prática.

\section{Abstract}

Objective: To understand Family Health team's practice from the perspective of virtue ethics.

Methods: A single case study of a qualitative approach, conducted between January and July 2019 in Family Health Strategies in a municipality in the countryside of Minas Gerais. Participants were physicians, nurses, nursing technicians and community health workers, totaling 35 professionals from Family Health Strategy teams. Data were collected through interviews and observation and analyzed through content analysis, with the help of atlas.ti software.

Results: Family Health team's practice is developed by care centered on users, in the search to meet their objective and subjective needs. However, there are obstacles that pass through the interface between legality/ bureaucracy (bureaucratic ethos) regarding compliance with standards recommended for service organization and operation and professional ethos related to professionals' commitment to people.

Conclusion: Family Health team's practice from the perspective of virtue ethics allows us to recognize that professional and patient are moral agents who are guided by values and virtues in the search for the internal good of their lives and practice. 


\section{Resumen}

Objetivo: Comprender la práctica del equipo de salud de la familia bajo la perspectiva de la ética de las virtudes.

Métodos: Estudio de caso único de enfoque cualitativo, realizado entre enero y julio de 2019, en Estrategia Salud de la Familia de un municipio del interior de Minas Gerais. Los participantes fueron médicos, enfermeros, técnicos de enfermería y agentes comunitarios de salud, que sumaron un total de 35 profesionales de los equipos de Estrategia Salud de la Familia. Los datos fueron recopilados mediante entrevistas y observación y analizados mediante el análisis de contenido, con ayuda del software Atlas.ti.

Resultados: La práctica del equipo de salud de la familia se desarrolla mediante el cuidado centrado en los usuarios, buscando satisfacer sus necesidades objetivas y subjetivas. Sin embargo, existen obstáculos que transitan la interfaz entre la legalidad/burocracia (ethos burocrático), relacionado con el cumplimiento de normas recomendadas para la organización y el funcionamiento del servicio, y el ethos profesional, relacionado con el compromiso de los profesionales con las personas.

Conclusión: La práctica del equipo de salud de la familia bajo la perspectiva de la ética de las virtudes permite reconocer que profesional y paciente son agentes morales que se guían por valores y virtudes en la búsqueda del bien interno de su vida y práctica.

\section{Introdução}

A Estratégia Saúde da Família (ESF) surge como base organizadora para a reorientação do modelo assistencial da Atenção Primária à Saúde (APS), configurando o trabalho em saúde por meio da compreensão das múltiplas demandas advindas de indivíduos, famílias e comunidades que vivem e se organizam em diferentes contextos. ${ }^{(1)} \mathrm{A}$ ESF se desenvolve na vertente ampliada do cuidado integral à saúde, efetivamente focado na pessoa/família e orientado pelo trabalho interdisciplinar em equipe multiprofissional. ${ }^{(2)}$

No contexto da ESF é constituída a equipe de Saúde da Família (eSF), a qual é historicamente composta pelo enfermeiro, médico, técnico de enfermagem e pelos Agentes Comunitários de Saúde (ACS). O trabalho conjunto dessa equipe possui características específicas e se destina a um fim próprio, configurando o conceito de prática na perspectiva da Ética da Virtude.

A prática, sob tal prisma, se constitui em um conjunto de atividades estruturadas por arranjos sociais e centrada em objetivos que lhes são próprios (bem interno), dada pela sua história e tradição. ${ }^{(3)} \mathrm{O}$ bem interno da prática na saúde pode ser considerado como o "bem do paciente", concretizado na busca do indivíduo pelo alcance dos padróes de excelência da prática. ${ }^{(4)}$ Nessa lógica, compreender a prática da eSF significa transcender a sua concepção de um conjunto de habilidades técnico-operativas para a conotaçáo de um desempenho qualificado de uma variedade de tarefas, centrado na aplicação direta do conhecimento biotecnológico. ${ }^{(5)}$

A prática é configurada pela legalidade da ética (ethos burocrático) e pela ética da profissão (ethos pro- fissional). O ethos profissional, embora não abandone a deontologia (ethos burocrático), aspira a excelência com o enfoque nas pessoas, cujo benefício confere sentido à prática. ${ }^{(4)}$ Considerando a complexidade das relaçôes na eSF e a da pluralidade moral dos usuários e trabalhadores, é insuficiente recorrer somente aos códigos de ética profissional para realizar a prática, uma vez que eles apontam para regras externamente estabelecidas, isto é, apenas para o que é correto ou não fazer. ${ }^{(6)}$

Nessa perspectiva, considera-se que a ética deontológica não abarca todas as singularidades requeridas na prática da eSF, tornando-se necessário ampliar o olhar para outra abordagem ética neste contexto. Isto é, atentando para os aspectos subjetivos envolvidos que contribuem para o alcance da finalidade da prática, qual seja o cuidado integral centrado na pessoa/família. . $^{(2,7)}$

Embora a ESF se apresente como uma forma de operacionalizar a APS e de transformar a realidade, ainda possui fragilidades relacionadas à articulação com os demais serviços da rede de saúde, às condiçóes de trabalho inadequadas, ao ambiente altamente burocrático, à sobrecarga de trabalho e autonomia e ao reconhecimento insuficientes ${ }^{(8,9)}$ o que leva os profissionais da eSF, em muitas situaçóes, a se distanciarem do cuidado centrado na pessoa e, por não poderem exercer a sua prática, promovem sua descaracterização e invisibilidade.

Ademais, a prática da eSF precisa ser compreendida como uma unidade, cujos acontecimentos relativos a ela apenas se concretizam no todo e, o seu bem interno, compartilhado pelos componentes da equipe. Contudo, torna-se um desafio a constituição da prática como uma unidade na eSF, uma vez que, por ela ser 
composta de diferentes categorias profissionais, cada uma delas tem, também, seus bens internos específicos que configuram a sua prática profissional. Portanto, os bens da prática podem ser compreendidos do ponto de vista individual de cada categoria profissional ou do ponto de vista da prática multidisciplinar.

Percebe-se, portanto, a necessidade de os profissionais da eSF mobilizarem competências para ressignificarem as suas práticas, tornando-se indivíduos capazes de protagonizar as açôes manifestas na produção do cuidado, desvelando o convite para a ética da virtude. Para MacIntyre, virtude é "uma qualidade humana adquirida cuja posse e exercício tendem a permitir o alcance dos bens que são internos às práticas e cuja falta efetivamente impede de alcançar tais bens". ${ }^{(3)}$ Assim, as virtudes são características do agente moral incorporadas ao mundo dos valores que norteiam a prática na busca pela excelência. ${ }^{(4)}$

Considerando que a Ética da Virtude subsidia reflexóes sobre o desenvolvimento da prática da eSF e que a literatura não faz tal articulação, surge a questão norteadora do presente estudo: Como se dá a prática da eSF sob o prisma da ética da virtude?

O presente estudo objetivou compreender a prática da Equipe de Saúde da Família sob o prisma da ética da virtude.

\section{Métodos}

O estudo é de abordagem qualitativa, delineado pelo método de estudo de caso único integrado, realizado em unidades de saúde da família, de uma cidade de médio porte de Minas Gerais, Brasil. A abordagem qualitativa busca compreender o sentido que os sujeitos atribuem a suas açóes, em seu tempo e espaço, propondo visibilizar as experiências humanas em sua dimensão sociocultural, valorizando os fatos e significados de seus diversificados contextos. ${ }^{(10)}$

$\mathrm{O}$ estudo de caso se refere ao objeto da presente pesquisa que busca pela compreensão da prática da eSF, sendo considerada um fenômeno social, complexo, e contemporâneo em um contexto real, onde o investigador tem controle muito reduzido sobre os eventos. ${ }^{(11)}$

Os participantes da pesquisa foram profissionais que compóem a equipe básica da ESF, sendo eles: médicos, enfermeiros, técnicos de enfermagem e agentes comunitários de saúde. $\mathrm{O}$ município possui cinco regióes administrativas e 43 equipes de ESF, dessa forma, realizou-se sorteio aleatório por região administrativa para eleger as equipes participantes.

Para compor a população do estudo foram incluídos na pesquisa profissionais com, no mínimo, seis meses de atuação na equipe, período considerado necessário para que eles pudessem vivenciar o ambiente de trabalho, as relaçóes e as atividades que compóem a sua prática. Foram excluídos do estudo, profissionais que estavam em gozo de licença saúde ou férias durante o período de coleta de dados.

Cabe salientar que o número de participantes não foi indicado a priori e a coleta de dados foi interrompida quando ocorreu a saturaçáo dos dados para cada categoria profissional, ou seja, quando as informações, após a análise, apresentaram a abrangência dos participantes, valorizando os conteúdos significativos para o estudo. ${ }^{(10)}$ Desta maneira, as entrevistas foram realizadas com 09 enfermeiros, 09 Técnicos de Enfermagem, 07 médicos e 10 Agentes Comunitários de Saúde (ACS), totalizando 35 profissionais.

A coleta de dados ocorreu entre os meses de janeiro a julho de 2019, por meio de duas fontes de evidência: entrevistas guiadas por roteiro semiestruturado e observação não participante. As entrevistas foram previamente agendadas e realizadas individualmente, em ambiente reservado nas unidades de saúde onde os profissionais estavam lotados, foram gravadas e tiveram duração média de 28 minutos. As questóes norteadoras das entrevistas abordaram o significado do trabalho na ESF; o relato da prática profissional e dos valores que a norteiam no contexto da ESF. As observaçôes foram realizadas durante todo o período da coleta dos dados, em momentos anteriores ou posteriores às entrevistas, na recepção, nos consultórios médico e de enfermagem, na sala de cuidados básicos e nas visitas domiciliares. As observaçóes foram registradas e identificadas como notas de observação (NO).

Para análise dos dados foi utilizada a Análise de Conteúdo Temática, seguindo os três polos cronológicos propostos por Bardin, com o auxílio do Atlas.ti 8. O software de análise de dados qualitativos foi utilizado como um instrumento operacional para a análise das entrevistas, favorecendo no processo de organização dos 
dados, permitindo às pesquisadoras uma visão panorâmica das descobertas durante o processo analítico. ${ }^{(12)}$

A respeito dos polos cronológicos, o primeiro momento decorreu com a fase de pré-análise, em que foi realizada a leitura flutuante e exaustiva do material, o qual foi posteriormente inserido no programa, o que contribuiu para visualização e organização dos dados. $\mathrm{O}$ segundo momento foi a fase de exploração dos dados, na qual a utilização do software facilitou o gerenciamento do material, para criação de códigos e categorização, culminando na criação de famílias que deram origem às categorias do estudo. A última etapa foi a de inferência e interpretação, na qual os dados brutos passaram a ter significado mediante a inferência, interpretação e discussóes dos dados com a literatura e com o referencial teórico da Ética da Virtude. ${ }^{(13)}$

O estudo atendeu à resolução 466/2012 do Conselho Nacional de Saúde, teve a aprovação das instâncias devidas do município, por meio da Carta de Anuência Institucional e do Comitê de Ética em Pesquisa (CEP), sob o Parecer $n^{\circ}$ 2.285.857. Os participantes assinaram o Termo de Consentimento Livre e Esclarecido, manifestando sua concordância em participar da pesquisa bem como sua ciência frente aos possíveis riscos, benefícios ou incômodos. Para garantir o anonimato, optou-se por identificar os depoimentos com a inicial das categorias; (E) enfermeiro, (TE) técnico de enfermagem, (M) médico, e (ACS) Agente Comunitário de Saúde, seguidas dos números estabelecidos para cada entrevista.

\section{Resultados}

Os resultados revelaram que a prática da eSF desenvolve-se sob a perspectiva de uma atenção à saúde centrada no atendimento às necessidades objetivas e subjetivas da pessoa/do usuário, em seu contexto de vida. Além disso, evidenciaram que a organização do trabalho por vezes representa risco ao desenvolvimento da prática de excelência.

Os participantes E6, M3 e TE3 expressam em seus depoimentos que a centralidade das atividades que realizam é a pessoa/o usuário, demonstrando a busca pelo bem interno da prática da eSF.
A estratégia saúde da familia me atrai, porque me permite cuidar das pessoas de uma forma continua. (E6)

Tento prestar um atendimento digno, humanizado às pessoas que, muitas vezes, não têm condiçóes de ir a um grande centro para ter atendimento à saúde de qualidade. Então, significa ajudar o próximo com a humanização da saúde. (M3)

Tem pacientes que vem aqui todos os dias, eles não têm nada, só querem conversar, às vezes, só querem me ver. Eu também me coloco no lugar do paciente, eu nunca penso em mim, profissional. O paciente em primeiro lugar. Dai eu me sinto valorizada por eles gostarem de falar comigo e, eles saem satisfeitos pelo atendimento. (TE3)

Nesse sentido, M6 e M4 revelam que a prática centrada na população exige compreensão das reais necessidades dela, as quais são subjetivas e extrapolam as queixas clínicas padronizadas nos protocolos ministeriais (ethos burocrático), expressando o ethos profissional.

A gente pode ajudar muitas pessoas, não só na saúde. Eu acho que o médico de família interfere muito na vida do paciente. Às vezes, o paciente não precisa do médico, mas precisa mais ser escutado. Eu acho que, como médico da familia, consigo abranger muito mais do que só uma consulta, só a doença do paciente naquele momento. Eu cuido das pessoas! (M6)

Eu atendo muita gente, mas aprendi a sentar e ter uma relação mais de escuta com o meu paciente. Eu o deixo falar sobre suas necessidades. Nem todas relacionadas à saúde, algumas psicológicas, emocionais, familiares. Identifico que a maioria das pessoas não está normalmente doente. (M4)

A prática eSF também foi descrita pelos participantes M7, E3, TE2 e ACS3 mediante as atividades técnicas que realizam, revelando principalmente os elementos procedimentais congruentes com o ethos burocrático previsto como escopo de suas atribuiçôes como membros da equipe de saúde da família. 
Consulta, puericultura, pré-natal, visita domiciliar, atendo demanda, urgência, às vezes, ajudo outras unidades quando estão sem médico, só. (M7)

A minha prática aqui é realizar as consultas de enfermagem, ajudo também em todos os procedimentos de enfermagem, acolhimento. Minha prática é tanto administrativa como assistencial. Faço consulta de pré-natal, de citologia, avaliação das mamas, faço puericultura. Então, é uma prática cheia. (E3)

Minha prática profissional é aferir pressão, glicemia, realizar curativos, retirada de pontos, fazer visitas domiciliares para os acamados, auxiliar o atendimento do médico, da Enfermeira. (TE2)

Faço visitas domiciliares, pelo menos uma por mês para cada familia, arrumo a minha pasta de cadastros, as fichas dos prontuários dos pacientes, classificando quem é hipertenso e quem é diabético, quem é saúde mental, classifico o risco da família também. (ACS3)

Como observado nos depoimentos anteriores, os participantes definem que a centralidade da prática é a pessoa/o usuário. Contudo, M2, E9 e TE1 referem que a organização do trabalho na ESF se apresenta como obstáculo para o alcance do bem interno da prática da eSF. Tais obstáculos estão relacionados à ausência de insumos adequados para a necessidade do usuário e à predominância do caráter administrativo burocrático vivenciado pela equipe de saúde no cotidiano de trabalho da ESF, os quais definem o modo como os profissionais organizam suas açóes no contexto da prática.

Estipula-se mais ou menos 20 minutos para cada atendimento, mas eu acho que esse tempo deveria ser mais, porque o usuário, para ter um tratamento completo, requer fazer anamnese, por exemplo. $E$ importante deixar o paciente falar o que ele tem $e$ isso gasta tempo, se você não tiver esse tempo, não vai conseguir fazer o tratamento e o diagnóstico completo, e o acompanhamento como um todo, da melhor forma. (M2)
Temos uma demanda gigantesca de serviço administrativo. Infelizmente, nós enfermeiros, e eu acho que a maioria de nós pensa assim, ficamos muito limitadas para desempenhar nosso papel assistencial. Nosso sonho era ter um funcionário que cuidasse exclusivamente dessa parte administrativa, de marcar exames para os pacientes e agendar as consultas de pré-natal e preventivo para atingir metas por exemplo, para gente ficar mais voltado para o paciente. (E9)

Atualmente, não tenho condiçóes de trabalhar. Estou aqui ainda porque gosto, faço o que gosto. Mas, não tenho condiçóes de trabalhar, de dar atendimento decente e respeitoso ao paciente. Estou ligando para todas as unidades, para pedir emprestado um equipo, seringa, medicação dipirona, porque a criança que está lá fora esperando, está com 39 de febre. (TE1)

Além dos depoimentos, durante observação realizada pela pesquisadora evidenciou-se o cancelamento de uma agenda de seis consultas de puericultura para substitui-la por outra de exames de citopatológico do colo do útero, a fim de que a unidade cumprisse a meta desse atendimento para aquele mês (NO). Tal ação, revela que a organizaçáo do trabalho não enfoca apenas a necessidade da pessoa/do usuário como centralidade, mas a exigência burocrática de metas e indicadores, sendo, portanto, um obstáculo para o alcance do bem interno da prática pela eSF.

Outro obstáculo para o desempenho da prática foi citado por E7 que refere os conflitos oriundos dos relacionamentos interpessoais que dificultam a construção de uma unidade na eSF.

Vivencio dificuldades também de relacionamentos que, às vezes, por trabalharmos com pessoas, atendermos pessoas, cada um com sua personalidade e seus objetivos, que, às vezes não são os mesmos, gera conflitos. Como a responsável técnica da equipe, tenho que assumir algumas posturas que contrariam o nosso colega de trabalho. (E7)

A respeito do relato da participante E7, a pesquisadora identificou situações de conflito entre a deliberação pretendida pela enfermeira e aquela pretendida pelo médico em relação à renovação de re- 
ceita de medicamento controlado para uma senhora idosa da área de abrangência. $\mathrm{O}$ médico não quis ouvir a justificativa de renovação da receita naquele momento, alegando que aquele não era o dia de realizar essa atividade. Enquanto a enfermeira já havia conversado com a usuária e identificado que ela havia passado por uma internação hospitalar e, por isso não renovou a receita antes, ficando sem medicaçôes para a continuidade do tratamento (NO).

Por outro lado, a enfermeira E1 e TE1 relatam boa experiência em compartilhar o trabalho com outros profissionais da equipe na busca pelo melhor cuidado a ser ofertado para o usuário, evidenciando a busca pelo bem interno da prática.

Eu tinha uma paciente que usava muito o nosso serviço. Ela vinha aqui diariamente. Estava acompanhada e medicada pela nossa médica. No entanto, sempre vinha à nossa unidade com alguma queixa. Então, a médica e eu decidimos realizar uma visita domiciliar para entender o que estava acontecendo, já que do ponto de vista assistencial clínico já não tinhamos mais o que fazer. Acionamos a ACS e realizamos a visita domiciliar. Na casa dela, identificamos que a medicação estava sendo tomada de forma errada. Como ela tomava muitos remédios, separamos todos, entre manhä, tarde e noite e, novamente a orientamos sobre a forma correta de se fazer. Combinamos da ACS realizar visitas semanais para ela, para verificar como estava o tratamento. Dessa forma, cuidamos dela mais de perto e ainda descobrimos como ela vive, do que se alimenta. (E1)

Uma vez acompanhamos uma paciente que já tinha uma ferida aberta, há dois anos. Nosso trabalho de equipe, graças a Deus, nos possibilitou fechar a ferida dela. O médico da nossa equipe também era muito bom, tinh a uma parceria muito boa, ele dava a liberdade para gente conversar, discutir o caso. Ele tinha a humildade de admitir que não entendia nada de curativo, e nos pedia sugestóes. Isso é muito gratificante! Nos dá motivos para acreditar que trabalhar em equipe pode fazer a diferença. (TE1)

Outro aspecto de destaque da prática da eSF foi citado por E5, ACS1, E6 e TE1, o qual se refere à importância de valores como dignidade, ética, empatia, sensibilidade, confiança, integralidade da atenção, vínculo, carinho, conhecimento, como balizadores para realizarem a prática do cuidado centrado na pessoa/no usuário no contexto da ESF.

Falando de ética a gente tem que ter sensibilidade para entender o paciente. Então, a integralidade, ética, saber se colocar no lugar do outro, ter empatia, tudo isso é importante na nossa profissão, principalmente aqui na ESF, pois lidamos mais tempo com os pacientes, conhecemos a realidade deles. (E5)

As pessoas confiam muito na gente, elas contam coisas, elas se abrem! Dessa forma, a gente cria um vinculo muito grande com as familias, eles confiam a vida deles para gente. A gente entra na casa deles, sabemos tudo de lá. (ACS1)

Tento ir pelo lado da integralidade, olhar o ser humano de uma forma integral, o máximo que eu consigo, e nunca fragmentar, porque principalmente na ESF a gente tem que tentar olhar de uma forma mais complexa né? Até mesmo, porque quando a gente está aqui mais próxima, a gente cria vínculo e tem uma série de fatores que conseguimos ver melhor $e$ atender de uma forma mais completa. (E6)

Meus valores principais são, primeiro o conhecimento que adquiri no curso de medicina e a atenção e o carinho que eu tenho em atender o paciente. Eu tenho carinho e atenção pelos pacientes, eu procuro resolver os problemas de saúde no atendimento do dia, inclusive eu gasto um tempo a mais, o que costuma atrasar no tempo das minhas consultas, porque às vezes o paciente tem muito mais queixas sociais que biológicas. (M2)

Percebe-se que os profissionais mesmo em face de obstáculos no cotidiano de trabalho da eSF buscam desempenhar a prática com excelência e centrada na pessoa/no usuário. Nesse sentido, ACS3 expressa a importância da busca primária pelo alcance da prática e de seus valores em detrimento das recompensas que ela pode proporcionar, como o dinheiro. 
Trabalho com ética. Eu me vejo no lugar do paciente, e isso é muito importante! Tem pessoas que trabalham só por dinheiro. Eu acho que a pessoa tem que trabalhar por amor ao que faz, ela tem que escolher uma profissão certa, porque se não, se escolher só por dinheiro, é muito ruim. (ACS3)

O presente estudo revelou que, os profissionais eSF embora vivenciem obstáculos para a efetivação de sua prática, buscam desenvolvê-la direcionada às necessidades objetivas e subjetivas dos indivíduos/ famílias, isto é, uma prática centrada na pessoa/no usuário. Relatam também a importância da prática em equipe e de valores como fundamentos para o cuidado centrado na pessoa/no usuário, no contexto das ESF.

\section{Discussão}

Por prática entendemos o trabalho em saúde estruturado por arranjos sociais e, centrada em objetivos que lhes são internos. ${ }^{(3)}$ Além disso, a prática também é compreendida pela aplicação do conhecimento em situaçóes concretas, que traz consigo um fim determinado que responda a um projeto de sociedade em que estão permeadas concepçóes de saúde-doença-cuidado. ${ }^{(7)}$ Considerar a eSF como prática significa dizer que, por meio do exercício profissional, enfermeiros, médicos, técnicos de enfermagem e agentes comunitários de saúde buscam a realização do cuidado integral centrado na pessoa/ família como o bem interno.

$\mathrm{Na}$ perspectiva dos profissionais do presente estudo, a compreensão das necessidades de saúde da população deve estar pautada para além das demandas clínicas padronizadas por protocolos e pela intervenção nos corpos biológicos. Salienta-se que o bem interno da eSF precisa ampliar a perspectiva do modelo biológico e tecnicista, para a compreensão da natureza instituinte dos arranjos singulares que estruturam o funcionamento das ESFs capaz de influenciar os modos de ser, de viver e de produzir cuidado nesse contexto da rede de atenção à saúde.

Nessa vertente, este estudo dialoga com outras pesquisas que buscaram compreender como se con- figura o trabalho nas ESFs, concentrando-se na potencialidade da dimensão subjetiva do modo de produção em saúde, integrando o mundo dos valores, dos sentimentos e dos aspectos éticos e culturais. ${ }^{(7,9)}$ A subjetividade relacionada ao cuidado no contexto das relaçóes das eSF, "é marcada por uma constante desconstrução e construção de territórios existenciais, segundo certos critérios que são dados pelo saber, mas também e fundamentalmente seguindo a dimensão sensível de percepção da vida, e de si mesmo, em fluxo de intensidades contínuas entre sujeitos que atuam na construção da realidade social". ${ }^{(7)}$

Para isso, a eSF precisa ampliar sua capacidade criativa e imaginativa, bem como sua sensibilidade humana e entendimento compreensivo das questôes da saúde e sociais a fim de incorporar reflexóes e açóes sobre novos temas e problemas e expressar sua capacidade para lidar com a complexidade inerente à pessoa e/ou a comunidade. ${ }^{(4,14)}$ As expressóes da prática da eSF, centrada no cuidado as pessoas/família, evidenciam o enfoque no ethos profissional, cuja abordagem das atividades está nas pessoas. ${ }^{(4)}$

Sob o prisma da Ética da Virtude, importa esclarecer que, para alcançar o bem interno da prática, os profissionais precisam incorporar, no cotidiano do trabalho, as virtudes compreendidas como a excelência do caráter ${ }^{(3)}$ e, identificadas como um ingrediente necessário para o encontro do profissional de saúde com o usuário. ${ }^{(15)}$ A virtude profissional é a disposição ou característica de caráter que permite ao agente moral agir para o bem, perseguindo a meta de uma atividade específica. O virtuoso em uma profissão é, portanto, aquele que na busca pelo telos da prática aspira ser o melhor e o mais competente possível. ${ }^{(3)}$

Nessa perspectiva, os resultados do presente estudo apontaram que os profissionais da eSF impelem valores às suas açóes como virtudes importantes no desempenho da prática. Assim sendo, valores como o respeito, a justiça, o cuidado, a empatia, a humildade, a responsabilidade e a integralidade apareceram como norteadores dos elementos ético morais da prática da eSF, potencializando o alcance do bem interno.

Estudo que buscou identificar os valores que orientam a enfermagem como prática social correspondem com os achados dessa pesquisa ao revelar que para o bem cuidar, faz-se necessário lançar o 
olhar para a integralidade da assistência à saúde. Tal situação demanda do profissional a compreensão do contexto social por meio da empatia, a promoçáo de um espaço de interação dialógica entre usuários, comunidade e equipe e a identificaçáo das necessidades de saúde e expectativas das pessoas, a partir da escuta qualificada. ${ }^{(7)}$ Infere-se então, que a integralidade se delineia como um princípio fundamental da atenção à saúde e que reverbera na prática como uma virtude, isto é, implica no compromisso com uma atenção resultante da prática construída socialmente entre profissionais e usuários, direcionada às necessidades objetivas e subjetivas das pessoas em seu contexto social, apreendidas e transformadas em açóes pela eSF, em consonância com o bem interno da prática.

O estabelecimento do vínculo e da confiança são virtudes marcantes nas relações entre equipe e usuários e, foi externado nesta pesquisa, pelos laços de carinho e atenção que fortalecem e estreitam as relações, tornando-as profícuas para a cooperação mútua entre as pessoas da comunidade e os profissionais da eSF na produção de saúde.

Autores têm destacado que dentre as potencialidades do trabalho da eSF aquelas relacionadas às tecnologias leves, como o vínculo e o acolhimento, demonstram grande efetividade para práticas horizontalizadas balizadas pelo compromisso mútuo, responsabilidade e intimidade, favorecendo o cuidado e a afinidade interpessoal. ${ }^{(7,16)}$ Ainda, apontam que tais estratégias são fortalecedoras da empatia e da relaçáo de confiança entre o profissional de saúde e o usuário, auxiliando na construçáo de autonomia dos usuários. ${ }^{(16,17)}$

Contudo, os participantes da presente pesquisa revelaram circunstâncias nas quais o cuidado centrado no indivíduo/família era preterido pelo excesso de demandas administrativas e procedimentais com consequente sobrecarga de trabalho. Na mesma direção, um estudo realizado com enfermeiros de eSF revela que a prática é fragilizada em decorrência de alta demanda de atendimentos e da sobrecarga de serviços não privativos do enfermeiro, distanciando os profissionais do contato contínuo e íntimo com o paciente, revelando a não concretização da prática idealizada e considerada correta. ${ }^{(18)}$

Foram também mencionados aspectos relacionados à organização e à gestão das ESFs como obstáculos à concretização da prática da equipe. A precariedade nas condiçóes materiais de trabalho, a sobrecarga de trabalho, o limite do tempo para a assistência ao paciente e as relaçóes interpessoais redirecionam o fazer profissional para o foco das normas vigentes e, para o alcance das metas impostas, evidenciando o ethos burocrático.

A esse respeito, vale ressaltar que as atividades técnicas e administrativas, de gestão e organização do trabalho também compóem o que se caracteriza como prática para a eSF, sendo parte do ethos burocrático da prática. ${ }^{(4)} \mathrm{O}$ que não pode acontecer é a priorização da realização do ethos burocrático em detrimento ao ethos profissional o que dificultaria a busca pelo bem interno e descaracterizaria a prática da $\mathrm{eSF} .{ }^{(3)}$ Estudo que evidenciou a recorrência de fragilidades na organização e nas relações da eSF demonstraram que os profissionais participantes enfrentavam diariamente situaçóes que contradiziam seus preceitos éticos de cuidado integral e contínuo as pessoas, o que possibilitou vivencias de Sofrimento Moral. ${ }^{(8)}$

Logo, a eSF, em sua prática, precisa conjugar o conhecimento científico, as habilidades técnicas e as normas legais das profissóes às relaçóes interpessoais, as quais, por sua vez, devem ser permeadas por valores que orientam a busca pelo cuidado centrado na pessoa. Entende-se, portanto, que a prática da eSF deve se configurar na convivência da legalidade (ethos burocrático) e da ética (ethos profissional). ${ }^{(4)}$ Dessa maneira, a prática virtuosa da eSF deve promover a escuta empática, a sensibilidade emocional e o reconhecimento da singularidade de cada usuário, aliada ao conhecimento, evidências científicas, e habilidades técnicas.

Para tanto, sugere-se que sejam criados, nas unidades de saúde, momentos destinados à escuta e às discussóes sobre as dificuldades enfrentadas para a efetivação das práticas, possibilitando espaço para que as emoçóes, os valores morais e sentimentos sejam expressos, sobretudo, com a finalidade de promover açóes que possibilitem a redução dos obstáculos à prática ética. Além disso, recomenda-se a reorientação dos processos formativos dos profissionais, com ênfase para a apresentação e valorização da ética da virtude como componente potencializador do desenvolvimento moral dos profissionais, com vistas ao aprimoramento da prática da eSF. 
Como limitaçóes do presente estudo, apontam-se que a prática da eSF foi explorada em uma cidade do interior de Minas Gerais, sugerindo que novas investigaçóes sejam desenvolvidas para explorar outros espaços, e a escassa literatura utilizando a ética da virtude como fundamentação epistemológica, especialmente no contexto da ESF. Salienta-se, no entanto, que, sendo a ética intrínseca à prática dos profissionais das eSF, os resultados desta investigação podem aplicar-se, subsidiando reflexóes acerca da construção de práticas profissionais que vislumbram o cuidado centrado no indivíduo considerado como o escopo do fazer em saúde.

\section{Conclusão}

O bem interno da prática da eSF foi explicitado pela procura constante dos profissionais em centralizar suas açóes nos usuários e buscar atender suas necessidades. Contudo, eles encontram obstáculos para alcança-lo devido ao excesso de burocracia, às falhas na organização dos serviços, às demandas excessivas, e à pressão do tempo. A eSF, por meio de virtudes, desempenha sua prática com a ampliação do olhar na direção da compreensão da singularidade de cada sujeito e da percepção integral de atenção às suas demandas objetivas e subjetivas.

\section{Agradecimentos}

Ao Conselho Nacional de Desenvolvimento Científico e Tecnológico - CNPq, processo no 302896/2016-3. À Fundação de Amparo à pesquisa do Estado de Minas Gerais - FAPEMIG, Programa de Pesquisa para o Sistema Único de Saúde, processo no APQ-03779-17.

\section{Colaborações}

Ferraz CMLC, Caram CS e Brito MJM colaboraram com a concepçáo do projeto, coleta dos dados, análise e interpretação dos dados, redação do artigo, revisão crítica relevante do conteúdo intelectual e aprovação final da versão a ser publicada.

\section{Referências}

1. Mendonça $\mathrm{MH}$, Matta GC, Gondim R, Giovanella L, organizadores. Atenção Primária à Saúde: conceitos, práticas e pesquisa. Saúde Debate. 2018;42(1)1:452-6. [resenha por Carlos dos Santos Silva].

2. Brasil. Ministério da Saúde. Portaria N².436, de 21 de Setembro de 2017. Aprova a Política Nacional de Atenção Básica, estabelecendo a revisão de diretrizes para a organização da Atenção Básica, no âmbito do Sistema Único de Saúde (SUS) [Internet]. Brasília (DF): Ministério da Saúde; 2017 [citado 2020 Jun 30]. Disponível em: https://bvsms. saude.gov.br/bvs/saudelegis/gm/2017/prt2436_22_09_2017.html

3. Maclntyre A. After virtue: a study in moral teory. 3rd ed. New York: Bloomsbury; 2013.

4. Cortina A. Cidadãos do mundo: para uma teoria da cidadania. São Paulo: Loyola; 2005.

5. Zoboli EL, Schveitzer MC. Nursing values as social practice: a qualitative meta-synthesis. Rev Lat Am Enfermagem. 2013;21(3):695-703.

6. Ferraz CM, Vilela GS, Moreira DA, Brito MJ. Moral sensitivity in the practice of Family Health Strategy professionals. Rev Rene. 2021;22:e60281.

7. Santos DS, Mishima SM, Merhy EE. Processo de trabalho na Estratégia de Saúde da Família: potencialidades da subjetividade do cuidado para reconfiguração do modelo de atenção. Cien Saude Coletiva. 2018;23(3):861-70.

8. Cardoso CM, Pereira MO, Moreira DA, Tibães HB, Ramos FR, Brito MJ. Moral distress in family health strategy: experiences expressed by daily life. Rev Esc Enferm USP. 2016;50(Spe):89-95.

9. Costa IP, Moreira DA, Brito MJ. Meanings of work: artuculation whith mechanisms of risk and protection for resilience. Texto Contexto Enferm. 2020;29:e20190085.

10. Minayo MC. Amostragem e saturação em pesquisa qualitativa: consensos e controvérsias. Rev Pesq Qualitativa. 2017;5(7):112.

11. Yin RK. Estudo de caso planejamento e métodos. 5a ed. Porto Alegre: Bookman; 2015.

12. Brito MJ, Caram CS, Montenegro LC, Rezende LC, Rennó HM, Ramos FR. Potentialities of Atlas.ti for data analysis in qualitative research in nursing. In: Costa AP, Reis LP, Sousa FN, Lamas AM. Computer supported qualitative research. Switzerland: Springer International Publishing Switzerland; 2016. p. 75-84.

13. Bardin L. Análise de conteúdo. São Paulo: Edições 70; 2016.

14. Gomes D, Zoboli EL, Finkler M. Problemas éticos na saúde bucal no contexto da Atenção Primária à Saúde. Physis Rev Saúde Coletiva. 2019;29(2):e290208.

15. Scott PA. Nursing and ethical dimension of practice. In: Scott P, editor. Key concepts and inssues in nursing ethics. Deutschland: Springer; 2017. p. 1-13.

16. Santos RO, Romano VF, Engstrom EM. Vínculo longitudinal na Saúde da Família: construção fundamentada no modelo de atenção, práticas interpessoais e organização dos serviços. Physis Rev Saúde Coletiva. 2018;28(2):e280206.

17. Bain LE. Revisiting the need for virtue in medical practice: a reflection upon the teaching of Edmund Pellegrino. Philos Ethics Humanit Med. 2018;13(1):4.

18. Rezende LC, Caram CS, Caçador BS, Brito MJ. Nurses' practice in quilombola communities: an interface between cultural and political competence. Rev Bras Enferm. 2020;73(5):e20190433. 